\title{
Expectativas de jovens do ensino médio público em relação ao estudo e ao trabalho
}

Davisson Charles Cangussu Souza'

Daniel Arias Vazquez!

I- Universidade Federal de São Paulo, Guarulhos, SP, Brasil.

Contatos: davisson.souza@unifesp.br; dvazquez@unifesp.br

\section{Resumo}

0 artigo analisa as expectativas de jovens do ensino médio de escolas públicas em relação à continuidade dos estudos e à inserção no mercado de trabalho. 0 principal procedimento da pesquisa foi a aplicação de um questionário a 1363 estudantes da região metropolitana de São Paulo. Em diálogo com as teorias críticas de Althusser (1999), Bourdieu e Passeron (1975), e Baudelot e Establet (1975), partimos da hipótese de que esses jovens possuiriam alta expectativa de ingresso no mercado de trabalho e baixa expectativa de continuidade dos estudos. Por um lado, os dados revelaram que os jovens pesquisados pretendem seguir estudando, e inclusive ingressar no ensino superior. Porém, por outro lado, foram constatadas desigualdades significativas de expectativas e avaliação de chances segundo as seguintes variáveis: autodefinição de raça; escolaridade e tipo de ocupação dos pais/responsáveis; autodefinição na estrutura de classes; experiência atual e anterior de trabalho. Tais desigualdades revelam a existência de um teto de vidro que reduz as chances de ingresso no ensino universitário (principalmente nas universidades públicas), segundo o grupo social considerado. Este artigo demonstra que conciliar estudo com trabalho é visto como a maior dificuldade e, ao mesmo tempo, como a principal estratégia para obter o nível superior, considerando os efeitos das políticas recentes de ampliação da oferta das vagas públicas e privadas.

\section{Palavras-chave}

Educação e trabalho - Jovens - Ensino médio - Escola pública Ensino superior. 


\title{
Expectations of young people from public secondary education about study and work
}

\author{
Davisson Charles Cangussu Souza' \\ Daniel Arias Vazquez
}

\begin{abstract}
This article analyzes the expectations about study and work of secondary students from public schools. The main research tool was a questionnaire answered by 1363 students in the metropolitan area of São Paulo city. In dialogue with the critical theories of Althusser, Bourdieu and Passeron, and Baudelot and Establet, we started from the assumption that these young respondents have high expectations of entering the labor market and low expectations of continuing studies. However, the data revealed that the young people surveyed intend to continue studying, mainly by accessing higher education. Furthermore, we found significant inequalities of expectations and evaluation of chances related with: self-definition of race; the type of education and occupation of parents/guardians; self-definition in the class structure; current and previous experience in the labor market. Such inequalities reveal the existence of a glass ceiling that reduces the chances of entering higher education (mostly in public universities), according to the social group considered. This article shows that combining study with work is seen, at the same time, as the main difficulty and the main strategy to obtain a higher degree, considering the effects of recent policies to expand the supply of places in public and private universities.
\end{abstract}

\section{Keywords}

Education and work - Young people - Secondary students - Public school - Higher education.

I- Universidade Federal de São Paulo, 


\section{Introdução}

Diversas análises que se dedicam a explicar a trajetória educacional dos jovens costumam enfatizar questões como a taxa de escolaridade e o acesso ao ensino superior desse público, demonstrando como esses índices são devedores de aspectos como o atraso escolar, a renda familiar e a autodefinição de cor/raça (ANDRADE; DACHS, 2007; LIMA, 2012) ${ }^{1}$. Outro conjunto de pesquisas recentes vem buscando explicar a trajetória educacional e laboral dos jovens egressos do ensino médio, enfatizando o destino daqueles que, por diversos fatores, não logram dar continuidade aos estudos ${ }^{2}$.

Nosso intuito neste artigo é analisar o momento anterior, ou seja, quando os jovens ainda estão construindo suas expectativas de abandono/ continuidade dos estudos e de ingresso no mercado de trabalho. Para tanto, analisamos essa questão em uma etapa crucial, aquela que antecede a habilitação para a entrada na universidade. Em outras palavras, não buscamos problematizar o perfil do público que já ingressou na universidade nem daqueles que já abandonaram os estudos. Ao contrário, pretendemos compreender as expectativas profissionais e educacionais dos jovens na iminência de conclusão do ensino básico a partir das seguintes questões: como planejam sua trajetória, como avaliam suas chances e como antecipam estratégias para superar as dificuldades que esperam encontrar. Os teóricos clássicos da educação sustentam que a trajetória escolar e profissional dos jovens varia conforme a inserção de classe de sua família de origem, o que afeta suas expectativas com relação a uma educação prolongada. Pesquisas atuais vêm demonstrando que os diferentes níveis de renda familiar acarretam oportunidades desiguais de trabalho e

1- Os dados estatísticos dessas pesquisas se baseiam na Pesquisa Nacional por Amostra de Domicílios do Instituto Brasileiro de Geografia e Estatística (PNAD/IBGE), que definem como jovens a população de 15 a 24 anos.

2- Alguns autores chamam a atenção para o grupo dos que nem estudam nem trabalham (os nem-nem), destacando seu perfil predominantemente feminino e a maternidade como principal motivo da interrupção da trajetória escolar e laboral. Ver Cardoso (2013) renda entre os jovens (ANDRADE; DACHS, 2007; LIMONGI; SAMPAIO; TORRE, 2000; POCHMANN, 2004). Em diálogo com essas teorias e pesquisas, partimos da seguinte hipótese inicial: os jovens de escolas públicas (por conta de sua origem predominante nas camadas populares) possuem baixa expectativa de continuidade dos estudos (em geral, e de ingresso no ensino superior em particular, especialmente na universidade pública) e alta expectativa de ingresso no mercado de trabalho (por conta da necessidade de contribuir com a renda familiar).

Essas expectativas variariam ainda segundo os seguintes fatores: gênero e autodefinição de cor/raça dos entrevistados; escolaridade e tipo de ocupação dos pais/ responsáveis; autodefınição na estrutura de classes; experiência atual e anterior de trabalho. Assim, a expectativa de continuidade de estudos seria menor entre: homens e negros; aqueles cujos pais/responsáveis têm inserção laboral como assalariados manuais e possuem menor escolaridade; que se definem como "pobres"; que trabalham ou já trabalharam. Para testar essas hipóteses, aplicamos um questionário a 1.363 estudantes do ensino médio de escolas públicas da região metropolitana de São Paulo. Este artigo tem o intuito de apresentar os principais dados obtidos nessa enquete.

0 texto está dividido em quatro partes. Na primeira, apresentaremos um breve resumo do marco teórico que nos serviu de base para a construção das principais hipóteses. Na segunda, faremos uma síntese dos procedimentos de pesquisa e uma descrição dos dados obtidos com a aplicação do questionário. Na terceira, analisaremos os resultados para buscar compreender as expectativas e as estratégias dos jovens pesquisados para a continuidade/ abandono dos estudos e inserção no mercado de trabalho. Na última parte, problematizaremos nossa hipótese inicial a fim de compreender as dificuldades latentes que funcionam como um teto de vidro ${ }^{3}$ na trajetória do público pesquisado.

3- Metaforicamente, imaginando que a trajetória social fosse uma escada, um teto de vidro no meio não impossibilitaria a visualização dos degraus 


\section{Marco teórico e hipóteses}

Este artigo não se insere na linha de pesquisas de sociologia da juventude, que busca analisar as especificidades dos jovens como grupo social para explicar questões como a cultura e a identidade juvenil (DAYRELL, 2007). Também não dialoga com a psicologia da adolescência, que aborda as particularidades afetivas e cognitivas dessa faixa etária, embora reconheçamos a importância de algumas questões levantadas pelos estudos clássicos nessa área ${ }^{4}$. Nosso objetivo é problematizar a relação entre educação, trabalho e classes sociais, tomando o público juvenil como objeto, mas sem a pretensão de discutir o universo identitário ou psicossocial dos jovens.

Sobre o conceito de classe, entende-se que as análises sobre a formação recente de uma "nova classe média" no Brasil, difundidas por Neri (2010), não podem ser norteadas apenas pelo critério da renda, desconsiderando identidades, escolhas políticas e de estratégias de sobrevivência, as quais certamente norteiam, entre outras coisas, a formação das expectativas sobre estudo e trabalho, objeto de análise deste estudo.

Nesse sentido, estabeleceu-se como ponto de partida o diálogo com as teorias crítico-reprodutivistas, assim denominadas pelo filósofo da educação Dermeval Saviani, porque compreendem a educação como um fenômeno condicionado pelas práticas sociais, e que tem por função principal a reprodução da estrutura de classes $^{5}$. São três as teorias classificadas por Saviani nesse grupo: a teoria da violência simbólica de Bourdieu e Passeron, a teoria da

mais altos, mas dificultaria a passagem para atingi-los. No sentido que procuramos dar a nosso texto, o teto de vidro seria o conjunto de barreiras com as quais não se conta como decisivas ao longo do percurso.

4- Piaget e Inhelder (1976), por exemplo, observaram que a adolescência é marcada pela revivência do "egocentrismo infantil" e pela "megalomania", pois se trata de um período de prevalência da assimilação sobre a acomodação, o que acarreta uma dificuldade de reconhecimento das condições objetivas de realização dos desejos individuais.

5- 0 autor diferencia as teorias crítico-reprodutivistas das teorias nãocríticas (Ensino Tradicional, Escola Nova e Escola Tecnicista), que concebem a educação como um instrumento de equalização social. escola como aparelho ideológico de Estado de Althusser e a teoria da escola dual de Baudelot e Establet (SAVIANI, 2009). Apresentaremos a seguir uma breve síntese dessas teorias, a fim de expor alguns questionamentos para o nosso objeto de estudo.

Althusser (1999) critica o mito da escola única e neutra para defini-la como um aparelho ideológico de Estado necessário para a reprodução das relações de produção. Para o autor, além da inculcação da ideologia burguesa dominante, a escola cumpre um papel fundamental na estrutura de relações de classe, por meio da formação da força de trabalho, distribuindo desigualmente os agentes segundo a função desempenhada na estrutura social (produção, repressão, ideologia e exploração).

Baudelot e Establet (1975) partem da análise althusseriana para afirmar que, além da difusão da ideologia dominante, a escola cumpre o papel ideológico de recalcamento da ideologia proletária. Os autores argumentam que o sistema de ensino nas sociedades capitalistas funciona de maneira dual por meio de duas redes, que correspondem à divisão fundamental da sociedade capitalista entre as duas classes principais (burguesia e proletariado). Denominam a primeira de rede PP (primáriaprofissional), voltada para a classe dominada, e a segunda de SS (secundária-superior), voltada predominantemente para a classe dominante.

No Brasil, Saes (2005) procura demonstrar que a defesa da escola pública, universal e gratuita e a difusão do mito da escola única expressam os interesses da classe média (definida como o conjunto dos trabalhadores assalariados não-manuais $)^{6}$. Segundo o autor, o apego à estratificação social (hierarquia salarial), justificada pela ideologia da meritocracia, é o que diferencia a classe média tanto da classe operária como da burguesia e da pequena burguesia, cuja ideologia típica é o apego à propriedade privada.

6- Vale ressaltar que o conceito de classe média não é empregado por Décio Saes em seu sentido mais habitual, ou seja, como estrato socioeconômico baseado em faixas de renda. 
A ideologia da meritocracia teria a função de encobrir os interesses específicos da classe média (a distinção em relação ao trabalhador manual). Por isso, concretiza-se na defesa do mito da escola única e para todos, baseada na noção de igualdade de oportunidades aplicada ao terreno educacional. Saes (2005) ressalta que a estratégia típica da classe operária é a inserção no mercado de trabalho, enquanto a da classe média é a escolaridade prolongada. De tal forma que, se a ideologia tipicamente burguesa é a ideologia da propriedade privada (já que o patrimônio e a herança são os principais mecanismos reprodutores de sua classe), a ideologia da meritocracia é a ideologia típica de classe média, pois serve ao propósito de encobrir a valorização do trabalho intelectual em detrimento do trabalho manual, a partir da noção de distribuição desigual de dons e méritos individuais. Dessa forma, seria possível concluir que: se a trajetória escolar não se conforma como uma estratégia típica da classe operária, suas expectativas em relação ao prolongamento dos estudos seriam baixas.

Bourdieu e Passeron (1975) questionam a noção de que o desempenho escolar esteja relacionado a dons, talentos, aptidões e méritos pessoais. A principal conclusão dos autores neste trabalho é de que, ao invés de ser um instrumento de mobilidade, a escola é um poderoso meio de conservação social. Assim, a principal função ideológica do sistema de ensino é justamente o ocultamento de sua função objetiva: a reprodução das relações da estrutura de classe (por meio da distribuição desigual de capital econômico, social e cultural), fazendo com que as hierarquias sociais apareçam como hierarquias escolares.

Porém, apesar da aparente igualdade de oportunidade e de acesso, a desigualdade educacional está condicionada pela desigualdade presente na estrutura social. De acordo com Bourdieu e Passeron (2005, p. 161),

[...] a maioria daqueles que, em diferentes fases do curso escolar, são excluídos dos estudos se eliminam antes mesmo de serem examinados e (...) a proporção daqueles cuja eliminação é mascarada pela seleção abertamente operada difere segundo as classes sociais.

Para problematizar a noção de expectativas que utilizamos neste artigo, vale mencionar o conceito de esperança subjetiva, definido pelos autores como o "produto da interiorização das condições objetivas que se operam segundo um processo comandado por todo o sistema de relações objetivas nas quais ela se efetua", e que estaria na base da explicação da "mortalidade escolar das classes populares” (p. 166).

Nesse sentido, as expectativas não podem ser consideradas como sinônimo dos desejos pessoais, mas como o resultado da tensão entre estes e o reconhecimento social das condições objetivas, dependentes em última instância da posição na estrutura social (hierarquia socioeconômica e escolar). Porém, os sujeitos nem sempre são completamente conscientes das dificuldades encontradas, por exemplo, para aceder ao ensino superior, seja pelos limites estruturais (número de vagas existentes), seja por percalços apresentados em sua trajetória (reprovação no exame vestibular, impossibilidade de arcar com os gastos na universidade, ou abandono dos estudos pela necessidade de trabalhar).

Sendo assim, as expectativas dizem respeito ao planejamento de uma trajetória (as pretensões, a avaliação de chances, as estratégias), planejamento esse que não se confunde com a própria trajetória. É, ao contrário, um indicador da predisposição para uma trajetória futura. Tal como afirmam Bourdieu e Passeron (2005), a baixa expectativa (ou a "esperança subjetiva") seria um condicionante da "mortalidade escolar". Em outras palavras, o desalento provoca a autoeliminação (ou a eliminação sem exame), ou ainda, a "resignação à exclusão", que se traduz no reconhecimento de que "isto não é para nós".

Bourdieu e Passeron também nos instigam a pensar outra questão que será útil para a análise aqui proposta. Esses autores 
fazem referência à raridade dos títulos como um mecanismo de distinção social, já que a escolaridade prolongada é uma estratégia poderosa de distinção social e de obtenção de vantagens econômicas. Observando mais detidamente o caso brasileiro, podemos indagar: a recente expansão do acesso ao ensino superior encurtou a distância entre os jovens do ensino médio das escolas públicas e a universidade? ${ }^{7}$

Deve-se considerar que, além da mobilidade social recente, foram criadas políticas públicas voltadas à ampliação do acesso ao ensino superior, especialmente da classe trabalhadora, por meio do Programa de Financiamento Estudantil (FIES), da concessão de bolsa integral ou parcial pelo Programa Universidade para Todos (Prouni), ou, ainda, pela expansão recente das vagas nas universidades federais, com a instalação de campi no interior dos estados ou na periferia das regiões metropolitanas via Programa de Apoio a Planos de Reestruturação e Expansão das Universidades Federais (Reuni). Ainda assim, todos esses programas - os quais serão descritos adiante - ainda condicionam o acesso à universidade ao desempenho escolar.

Com base nas discussões feitas até aqui, partimos das seguintes hipóteses: a) os jovens da classe operária se resignariam à exclusão por meio da autoeliminação (a "eliminação sem exame"); desse modo, sua "esperança subjetiva” se traduziria em "incorporação das condições objetivas” específicas de sua classe (BOURDIEU; PASSERON, 1975); b) a escola, então, seria um mecanismo de reprodução das relações de produção, por reproduzir os diferentes agentes por meio de trajetórias escolares desiguais (ALTHUSSER, 1999); c) essas trajetórias expressam o funcionamento de um sistema de ensino dual (SS e PP), voltadas respectivamente para a burguesia e para o proletariado (BAUDELOT; ESTABLET, 1975);

7- Ressalta-se que essa expansão não significou a eliminação das hierarquias, que persistem entre os cursos e instituições (carreiras voltadas para a produção de tecnologia de interesse para a indústria x licenciaturas; universidades públicas de excelência $x$ faculdades privadas etc.). d) o interesse típico dos jovens de famílias oriundas da classe operária é a entrada no mercado de trabalho, enquanto a escolaridade prolongada é o interesse típico da classe média, que se utiliza da ideologia da meritocracia para se distinguir dos trabalhadores manuais e valorizar economicamente o trabalho intelectual, reproduzindo seus privilégios de classe (SAES, 2005).

Em síntese, os jovens de escolas públicas possuiriam baixa expectativa de continuidade dos estudos em geral (e de ingresso no ensino superior em particular, especialmente na universidade pública) e alta expectativa com relação ao ingresso no mercado de trabalho. Nesse sentido, o trabalho se imporia como uma necessidade (para contribuir com a renda familiar) e a interrupção da trajetória educacional seria uma fatalidade (por conta da impossibilidade de conciliar trabalho e estudo, da dificuldade de ingressar na universidade pública ou de pagar uma mensalidade em uma faculdade privada). Sendo assim, estariam nos planos da maioria desses jovens não o ensino superior, mas sim o ensino técnico ou até mesmo o abandono dos estudos.

\section{Procedimentos de pesquisa e descrição dos dados}

Para testar essas hipóteses no contexto brasileiro recente, aplicamos uma enquete a jovens do ensino médio de escolas públicas sobre suas expectativas em relação ao estudo e ao trabalho. A pesquisa foi realizada como parte das atividades da disciplina Estágio Supervisionado Em Ciências Sociais I, ministrada pelos autores deste artigo no segundo semestre de $2012^{8}$. Obtivemos 1558 casos. Desse total,

8 - A pesquisa foi aplicada pelos alunos da disciplina durante a visita às escolas. Vale destacar que esses estudantes realizaram estágio supervisionado de 50 horas nas respectivas escolas e que essa atividade de pesquisa era parte da ementa da disciplina e da proposta do referido estágio. Além disso, houve a incorporação como atividade da matéria de sociologia nas escolas pesquisadas, com participação e autorização prévia do professor responsável e do dirigente da escola (coordenador pedagógico e/ou diretor). Além de receberem as orientações fornecidas para a realização da pesquisa no estágio, os estudantes já haviam cursado 
excluímos 195 estudantes de escolas privadas e de Educação de Jovens e Adultos (EJA), pois se tratava de um número insuficiente para uma análise comparativa entre as esferas pública e privada e por faixa etária ${ }^{9}$. A análise preliminar desses casos permitiu constatar que os mesmos distorciam os dados gerais, visto que os estudantes do ensino privado avaliavam suas chances de ingresso no ensino superior como mais altas que o geral, e o público do EJA tinha bem menos pretensão de acesso à universidade do que o conjunto dos entrevistados ${ }^{10}$. Trabalhamos, então, com os 1.363 estudantes do ensino médio público regular.

0 questionário era composto por 22 questões divididas em quatro partes: 1) Perfil do entrevistado (sexo, autodefinição de cor/raça); 2) Perfil familiar (tipo de ocupação, profissão e grau de escolaridade dos pais/responsáveis); 3) Expectativas educacionais (pretensão de continuidade dos estudos e de ingresso no ensino superior, bem como a avaliação das chances, das dificuldades e das atuais políticas governamentais de acesso à universidade); 4) Expectativas no mercado de trabalho (experiências e pretensões profissionais).

Os dados foram obtidos em 35 escolas públicas de ensino médio da região metropolitana de São Paulo (RMSP). Desse total, 63,4\% dos casos estavam localizados na capital, 23,9\% em Guarulhos (município sede da universidade) e os $12,7 \%$ restantes em outros municípios. A média de idade do público foi de 16,3 anos, com variação de 14 a 21 anos.

\footnotetext{
a unidade curricular de Métodos e Técnicas de Pesquisa Quantitativa e, portanto, estavam devidamente capacitados para a aplicação do questionário, elaborado pelos autores deste estudo, e também para a tabulação dos dados. 0 banco de dados foi consolidado pelos autores e submetido a testes de consistência. Por fim, deve-se ressaltar que os resultados preliminares foram apresentados aos estudantes e também aos professores das escolas pesquisadas. Agradecemos o empenho dos estudantes durante a aplicação do questionário e as contribuições recebidas durante a apresentação preliminar dos dados.

9- Após a publicação deste artigo, o questionário e o banco de dados serão disponibilizados ao Consórcio de Informações Sociais (CIS) - http:// www.nadd.prp.usp.br/cis/index.aspx.

10- Desse modo, apesar de levarmos em conta a pertinência de uma análise comparativa entre esses públicos, essa questão ficará pendente para futuros trabalhos.
}

0 número médio de pessoas que habitam a residência dos entrevistados foi de 4,3. Os principais responsáveis pelo sustento familiar são os pais $(70,6 \%$ o pai e $72,1 \%$ a mãe), restando ainda 14,2\% para outro responsável (na maioria, algum familiar, principalmente os avós), 7,5\% para os próprios sujeitos, 1,48\% para o(a) esposo(a).

A incidência de jovens com filhos foi de 1,54\%, com variação de 1 a 2 filhos. Do total da amostra, 53,4\% eram do sexo feminino e $46,6 \%$ do sexo masculino. Com relação à raça/ cor da pele, 43,3\% se declararam brancos, $39,2 \%$ pardos, $11,8 \%$ pretos, 3,6\% amarelos e $2,1 \%$ indígenas ${ }^{11}$. Verificamos ainda um alto percentual de estudantes com experiência atual ou anterior de trabalho: 42,6\% trabalham ou já trabalharam, sendo 50,6\% dos homens e 35,7\% das mulheres ${ }^{12}$.

Com relação à classe social, a intenção inicial da pesquisa era captar a autopercepção dos jovens na estrutura social, e não fazer uma análise objetiva de sua inserção de classe. Dessa forma, optou-se por uma terminologia bastante conhecida: rico, pobre e classe média. Embora essa tipologia não seja consensual entre os pesquisadores, trata-se de uma classificação que tem a vantagem de se aproximar a um repertório conceitual mais conhecido dos jovens, o que não acontece com termos como burguesia, pequena burguesia e proletariado. Por outro lado, não adotamos a classificação A, B, C, D e E do Instituto Brasileiro de Geografia e Estatística (IBGE), para não ficarmos presos a critérios previamente estabelecidos de renda para a definição de classe, mesmo porque, segundo nossa hipótese, a maioria dos jovens não saberia informar a renda familiar dos pais/responsáveis.

A grande porcentagem de jovens que se consideram pertencentes à classe média $(75,1 \%)$ nos conduz à hipótese de que a difusão da noção

11- Essa variável foi construída com base nos critérios de classificação de cor/raça do IBGE.

12- Essa seria uma primeira evidência da centralidade do trabalho na vida do público pesquisado: 0 alto percentual de jovens trabalhadores. Esse fator possui ainda uma forte clivagem de gênero, tendo em vista a maior incidência de jovens do sexo masculino com experiência de trabalho. 
de nova classe média (e sua suposta expansão nos últimos anos), associada ao aumento do salário médio real e à elevação da capacidade média de consumo de bens duráveis (computador, celular, automóvel etc.), tem levado parte das camadas populares a se sentirem pertencentes a esse grupo. Segundo Neri (2010), “cerca de 29 milhões de pessoas ingressaram nas fileiras da chamada nova classe média (Classe C) entre 2003 e 2009" (p. 12), sendo que uma das características citadas pelo autor dessa "nova classe" é o "anseio de subir na vida", por meio de um "plano bem definido de ascensão social” (p. 26). Nesse sentido, espera-se que as expectativas reflitam certo otimismo e revelem uma estratégia para o alcance dos objetivos traçados, a qual passará pelo estudo e/ou trabalho.

De qualquer forma, embora o número dos que se consideram ricos seja muito pequeno (apenas 0,6\%), o percentual dos que se consideram pobres não é desprezível, chegando a quase um quarto da amostra (24,3\%). Por último, vale mencionar que a autodefinição como pobres varia consideravelmente segundo a autodeclaração de raça. Assim, se, do total de pretos, 33,5\% se consideram pobres, esse percentual cai para $18,6 \%$ entre os que se definem como brancos. Ou seja, apesar da possível distorção gerada pela tipologia escolhida, a variável será significativa para a análise a que nos propomos.

Com relação ao vínculo empregatício dos pais, o gráfico 1 mostra que, em ambos os casos, embora a maioria seja composta por empregados assalariados $(67,1 \%$ dos pais e $60 \%$ das mães), há maior incidência de mães na informalidade: enquanto, entre os pais, 58,8\% possuem carteira assinada e 8,3\% não possuem, entre as mães, 48\% possuem carteira assinada e $12 \%$ não possuem ${ }^{13}$. Também entre as mães se observa maior número de desempregadas (3,3\% contra $1,9 \%$ dos pais) e um grande percentual de donas de casa (19,9\%), situação quase inexistente entre os pais $(0,3 \%)$. É maior o percentual de pais autônomos e empregadores (respectivamente 17,1\% e 4,3\% contra 10,7\% e 2,0\% entre as mães).

13- Esses números são semelhantes aos apontadas pelos últimos relatórios da PNAD/IBGE.

Gráfico 1: Tipo de ocupação do pai e da mãe (em \%)

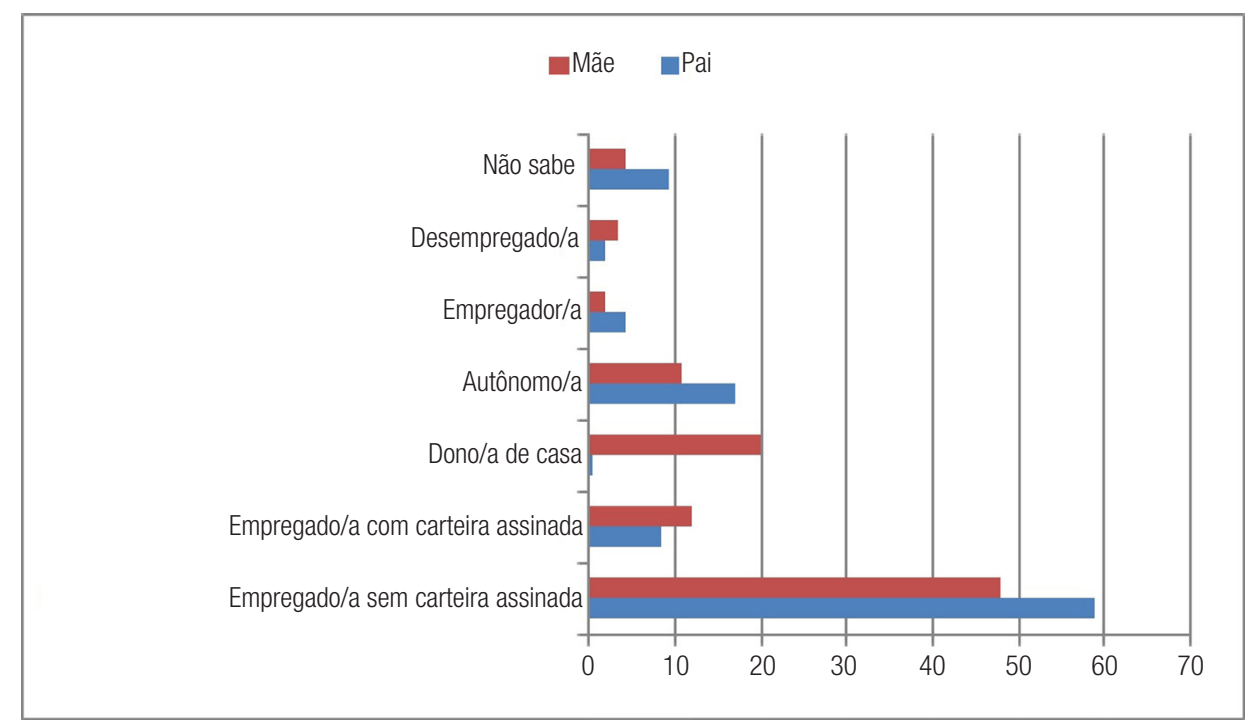

Fonte: Dados da pesquisa. 
Vale destacar, por último, que, em ambos os casos, prevalecem profissões relacionadas ao trabalho manual (na indústria, no comércio e nos serviços), sendo bastante frequente entre os homens o trabalho na construção civil, no setor de transportes e em serviços pessoais (pedreiro, motorista, porteiro, segurança etc.), e comuns entre as mulheres os serviços educacionais, domésticos e pessoais (professora, auxiliar de limpeza, costureira, cozinheira, empregada doméstica, diarista etc.). Em ambos os casos, foi muito baixa a incidência de profissionais não-manuais de nível superior (médicos, engenheiros, advogados etc.).

Com relação aos estudos, observou-se que a escolaridade das mães é maior que a dos pais. Embora a porcentagem seja semelhante nos primeiros níveis, há uma maior proporção de mães com ensino médio completo (32,2\% contra 28,2\% dos pais). Em ambos os casos, a porcentagem com ensino superior completo (com ou sem pós-graduação) é de pouco mais de 10\%, conforme mostra o gráfico 2 .

Gráfico 2: Grau de escolaridade do pai e da mãe (em \%)

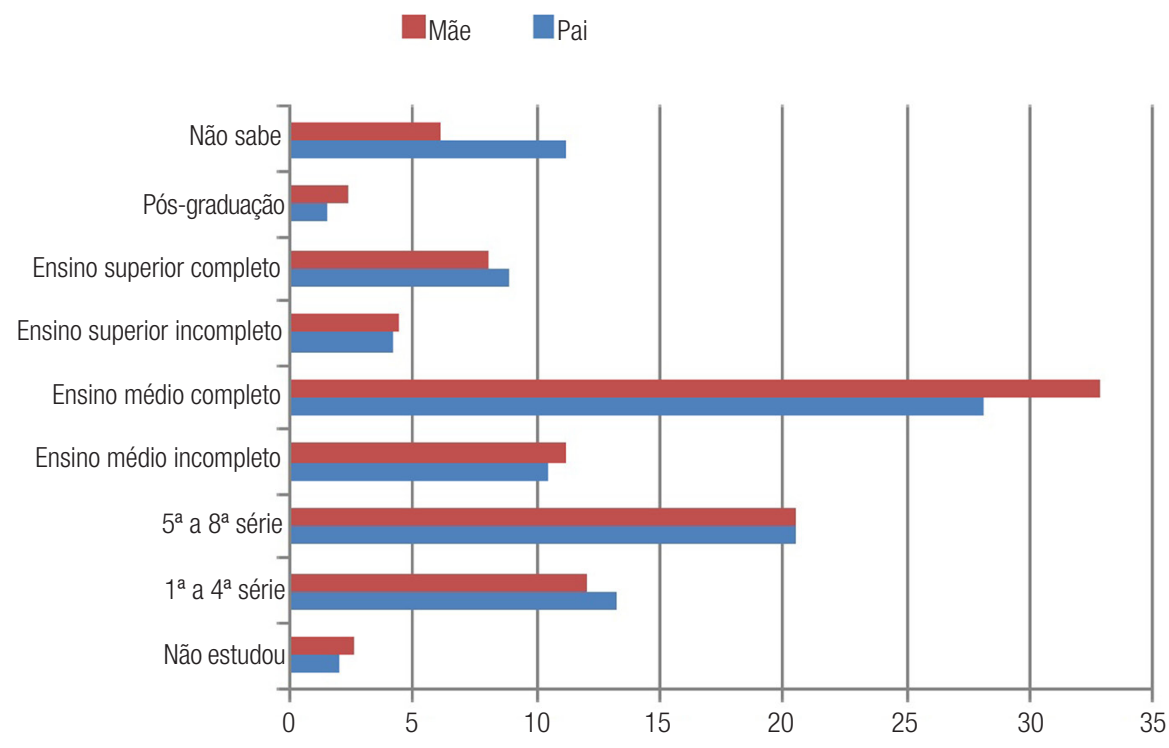

Fonte: Dados da pesquisa.

Vejamos a seguir como os jovens avaliam os estudos. Para 78,6\% dos entrevistados, o estudo é a principal forma de obter melhores possibilidades de emprego e salário; para 20\%, essa é uma via parcial, e somente para 1,4\% não se configura como uma forma de ascensão social. Ademais, 98\% informaram que a família apoia a continuidade de seus estudos, 1,3\% que apoia parcialmente e $0,7 \%$ disseram que não apoia. Com relação à expectativa de continuidade dos estudos, 94,3\% dos jovens entrevistados declararam que pretendem seguir estudando.
Em suma, a grande maioria dos jovens vê o estudo como principal via de ascensão social, informa que sua família apoia a continuidade de seus estudos e declaram pretender seguir estudando. Essa visão não se diferencia entre os que se consideram e os que não se consideram pobres, o que a princípio demonstra que o reconhecimento social da escolaridade e a estratégia do estudo como via de ascensão não são exclusivos da classe média, tal como as teorias crítico-reproduvistas nos fizeram supor. Porém, a estratégia do estudo não exclui 
a demanda por entrada no mercado de trabalho, já que 93,4\% pretendem começar a trabalhar ou seguir trabalhando após o ensino médio ${ }^{14}$.

Vale ressaltar mais detidamente o perfil das pretensões de continuidade de estudos dos jovens pesquisados. Entre os que pretendem seguir estudando, 83,9\% tencionam fazer faculdade, 25,3\% almejam fazer um curso técnico e $14,4 \%$ pretendem fazer outro tipo de curso ${ }^{15}$. Com relação ao tipo de universidade (se pública ou privada), há uma preponderância da dupla estratégia: pública, mas não descarta a privada $(55,1 \%)$; e privada, mas não descarta a pública $(26,5 \%)$. 0 foco na universidade pública é baixo (apenas 12,8\%), e o foco exclusivo nas faculdades privadas é ainda menor (5,5\%).

0 percentual alto de jovens que pretendem seguir estudando e ingressar na universidade pode ocultar outros dois fenômenos: o reconhecimento de barreiras e a avaliação das chances. Escolhemos três fatores para avaliar o julgamento que os jovens fazem das dificuldades que lhes são impostas para a continuidade de seus estudos após o ensino médio: a condição financeira, o desempenho escolar e a necessidade de trabalhar. 0 gráfico 3 mostra que esses fatores impõem diferentes graus de dificuldades para a continuidade dos estudos, na opinião dos jovens pesquisados.

Embora 31,8\% vejam a condição financeira e 33,9\% vejam o desempenho escolar como fatores que impõem alguma dificuldade para a continuidade dos estudos ${ }^{16}$, esse percentual sobe para 59,3\% no que diz respeito à necessidade de trabalhar. A menor incidência dos fatores condição fınanceira e desempenho escolar supõe que os jovens consideram que essas barreiras sejam mais facilmente superáveis do que a necessidade de trabalhar. No caso do fator condição financeira, é possível supor que a inserção no mercado de trabalho seja vista como um fator de possível superação dessa

Gráfico 3: Dificuldades para continuidade dos estudos

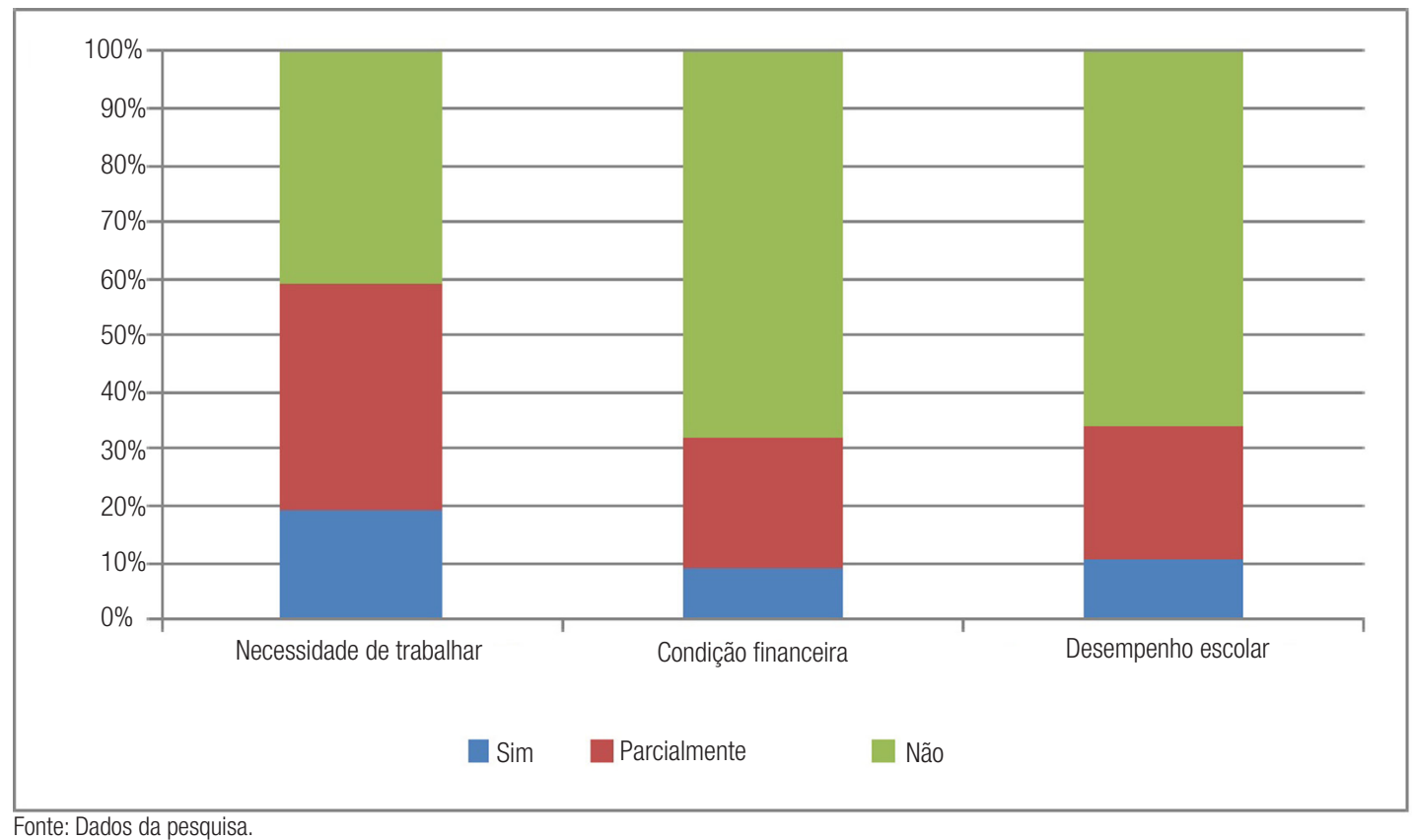

14- Esse dado nos leva a uma segunda evidência da centralidade do trabalho na vida desses jovens: a quase totalidade pretende começar a trabalhar ou seguir trabalhando.

15- Trata-se de questão de múltipla escolha, o que explica que a soma das respostas seja superior a $100 \%$. dificuldade. Se confirmado, esse dado seria mais uma evidência da centralidade do trabalho

16- Ou seja, aqueles que responderam sim ou parcialmente. 
na vida desses jovens. Testaremos essa hipótese mais adiante.

Vale chamar a atenção, no entanto, para como os entrevistados avaliam suas chances de ingresso no ensino superior. A grande porcentagem de avaliação de chances médias (76,5\% na universidade pública e $63,6 \%$ nas universidades privadas) indica que os jovens não são tão otimistas, mas também não veem como impossível o acesso à universidade, pois a avaliação de chances não chega a provocar o desalento e o total abandono do ensino superior de seu horizonte. Assim, da mesma forma que chama a atenção a pequena proporção de jovens que avaliam suas chances como altas (9,1\% na pública e 18,1\% na privada), também é notório o percentual de jovens que consideram que suas chances de ingresso na universidade não sejam baixas (14,4\% na pública e 18,3\% na privada) ${ }^{17}$.

Esse fator pode ter relação com as políticas recentes de acesso ao ensino superior. Segundo Catani, Hey e Gilioli (2006), o Prouni foi criado pelo governo como o carro-chefe na democratização do ensino superior, por meio de uma "engenharia administrativa que equilibra impacto popular, atendimento às demandas do setor privado e regulagem das contas do Estado" (p. 127), com base na concessão de bolsas de estudos integrais ou parciais nas instituições de ensino superior (IES) que aderissem ao programa, as quais seriam beneficiadas com isenção de tributos. Os bolsistas são selecionados por critério socioeconômico associado à nota obtida no Exame Nacional do Ensino Médio (ENEM), cuja dimensão cresceu bastante após a criação do Prouni.

Em seguida, o governo federal também cria o Reuni, com o objetivo de dobrar as vagas ofertadas na rede federal de ensino superior, com a criação de novas universidades e campi de expansão fora das capitais dos estados. Apesar da forma de ingresso manter-se baseada no desempenho escolar, a seleção passou a ser

17- Essa distorção pode ser resultante do fato de parte dos entrevistados ter avaliado suas chances de ingresso não só como as possibilidades de acesso mas também de permanência na universidade. feita via Sistema de Seleção Unificado (SISU), o que popularizou ainda mais o ENEM. Além disso, foram estabelecidas as cotas raciais e, mais recentemente, a Lei $\mathrm{n}^{\circ} 12.711 / 2012$ passou a reservar 50\% das matrículas por curso e turno para alunos egressos da escola pública e em proporção à população negra e indígena.

0 gráfico 4 mostra a percepção dos jovens entrevistados sobre os efeitos desses programas como facilitadores do acesso deles ao ensino superior. Na avaliação de 62,2\%, o ENEM aumentou suas chances de ingresso na universidade ${ }^{18}$, percentual que se reduz para $47,7 \%$ no caso do Prouni e 36,9\% no caso do SISU.

Gráfico 4: Avaliação do efeito das políticas públicas sobre a chance de ingresso na universidade (em \%).

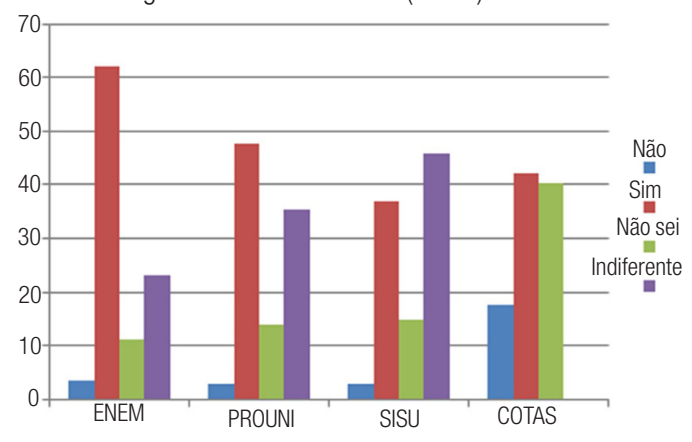

Fonte: Dados da pesquisa.

No entanto, o que também chama a atenção é a alta porcentagem de jovens que desconhecem essas políticas: 23,2\% desconhecem o ENEM; 35,5\% desconhecem o Prouni; e 45,7\% desconhecem o SISU. 0 maior grau de conhecimento do ENEM deve-se à utilização da nota desse exame tanto para o Prouni como para o SISU. Por fim, 42,1\% dos jovens consideram que as cotas para negros e para escolas públicas aumentaram suas chances.

Apesar da aparência de menor impacto das políticas de cotas, as diferentes avaliações segundo a autodefınição de classe e a autodeclaração de raça contribuem para

18- Vale mencionar que não há diferença estatística significativa entre autodeclarados pobres e não-pobres na avaliação do ENEM como política que teria aumentado as chances de ingresso ao ensino superior. 
complexificar a compreensão deste fenômeno, conforme as tabelas 1 e 2 .

Tabela 1: Avaliação das cotas entre os jovens autodeclarados como pobres (em \%)

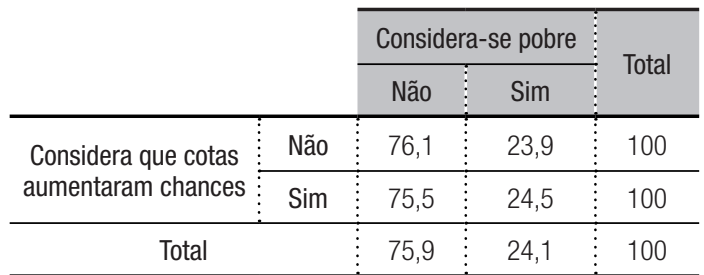

Qui-quad. $=0,570^{\mathrm{a}} \mathrm{df}(1)$ sig. 0,811

Tabela 2: Avaliação das cotas entre os jovens segundo autodeclaração de cor/raça (em \%)

\begin{tabular}{|c|c|c|c|c|}
\hline & & $\begin{array}{l}\text { Brancos e } \\
\text { Amarelos }\end{array}$ & $\begin{array}{l}\text { Pretos, Pardos } \\
\text { e Indígenas }\end{array}$ & Total \\
\hline \multirow{2}{*}{$\begin{array}{c}\text { Considera que } \\
\text { cotas aumentaram } \\
\text { chances }\end{array}$} & Não & 51,1 & 48,9 & 100 \\
\hline & Sim & 41,1 & 58,9 & 100 \\
\hline \multicolumn{2}{|l|}{ Total } & 46,9 & 53,1 & 100 \\
\hline
\end{tabular}

Qui-quad. $=12,908^{\mathrm{a}} \mathrm{df}$ (1) sig. 0,0

Observamos que, embora, entre aqueles que se consideram pobres, não haja diferença na avaliação de suas chances, o corte racial é significativo. Entre brancos e amarelos, 41,1\% considera que essa política aumentou suas chances, percentual que sobe para 58,9\% entre pretos, pardos e indígenas. Por fim, o gráfico 5 mostra com maior nitidez a diferença entre estes últimos, já que a porcentagem de pretos que consideram que suas chances aumentaram é de $60,4 \%$, enquanto entre os brancos é de 36,4\%.

Nossa argumentação até aqui demonstra que os jovens têm em seu horizonte a continuidade dos estudos (pretendem ingressar na universidade), reconhecem dificuldades para a continuidade dos estudos (principalmente a necessidade de trabalhar), mas não se resignam à exclusão: avaliam que as políticas de acesso ao ensino superior aumentaram suas chances (especialmente o ENEM e as cotas, para os jovens autodeclarados negros) e procuram montar uma estratégia para driblar as dificuldades que esperam encontrar.

Qual seria essa estratégia? Primeiramente, pretende-se verificar se os jovens consideram que podem se manter (e, se sim, de que maneira) tanto na universidade pública como na universidade privada, conforme mostra o gráfico 6.

Gráfico $\mathbf{5}$ - Avaliação de aumento das chances a partir das cotas, segundo a autodefinição de cor

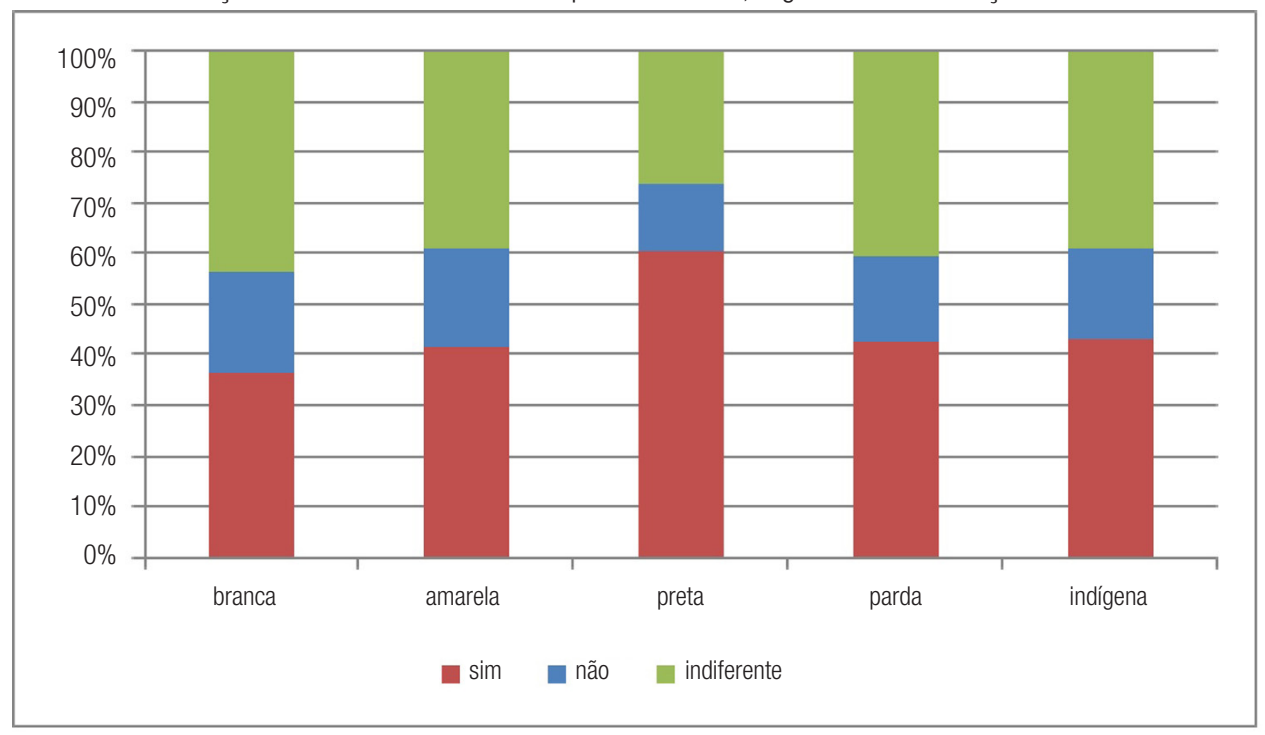

Fonte: Dados da pesquisa. 
Gráfico 6 - Condições de permanência e estratégias para seguir estudando (em \%)

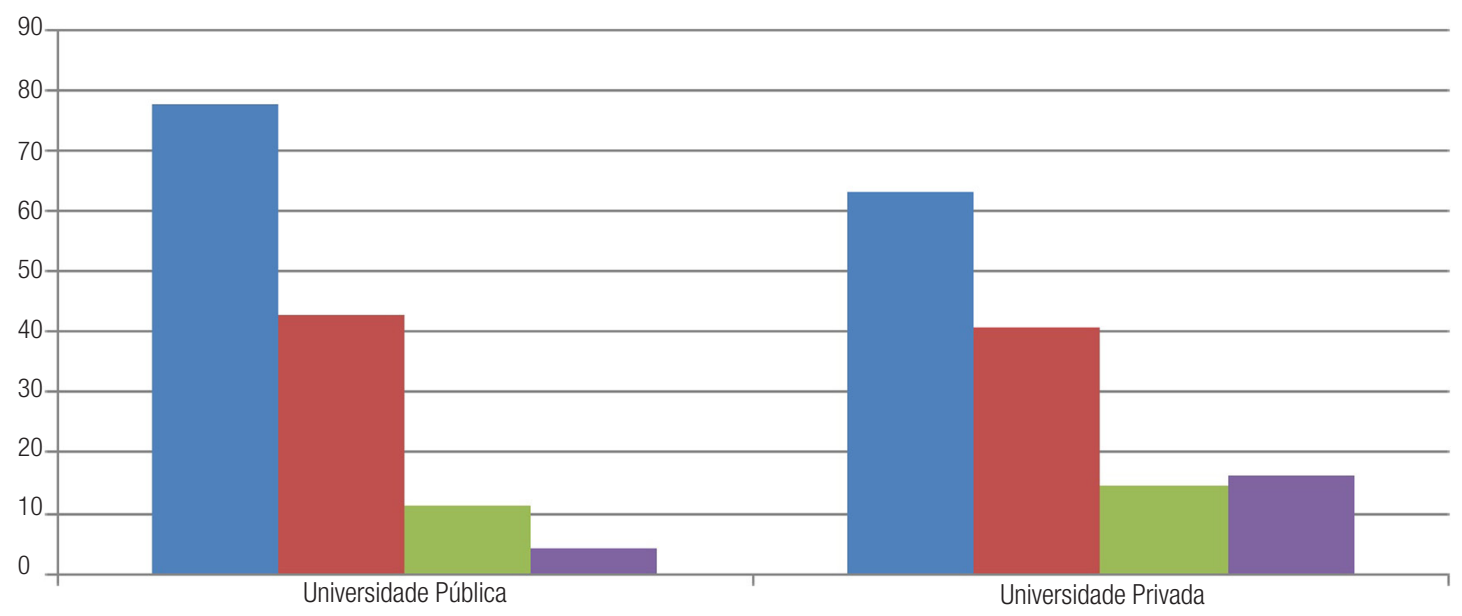

Pretende trabalhar

$\square$ Ajuda familiar

Assistência estudantil (se pública) ou financiamento (se privada)

—Sem condições de se manter

Fonte: Dados da pesquisa.

Como se pode observar, são poucos os que afırmam não poder se manter na universidade pública $(4,1 \%)$, percentual quatro vezes superior quanto à universidade privada $(16,1 \%)$, o que indica que o pagamento de uma mensalidade é um fator de exclusão mais expressivo que outros gastos com educação quando o ensino é gratuito. Embora o corte racial não explique a avaliação de chances de pagar uma mensalidade na universidade privada, considerar-se pobre implica uma menor expectativa em relação a essa questão $0^{19}$.

Dentre as estratégias para se manter na universidade, poucos mencionam as políticas de auxílio, seja a assistência estudantil nas universidades públicas $(11,3 \%)$, seja o financiamento estudantil nas universidades privadas (14,3\%). A ajuda familiar é um fator considerável na estratégia de manutenção

19- Entre os que se definem como pobres, $22,3 \%$ afirmaram não ter condições de pagar mensalidade, contra 16\% do total e 14\% dos que não se consideram pobres (Chi-Square Tests $=12,775$, df (1), sig. 0,000). Não houve diferença estatisticamente significativa entre brancos e não-brancos (Chi-Square Tests =0,4110, df (1), sig. 0,522). financeira dos jovens $(42,6 \%$ no caso da universidade pública e 40,8\% no caso da universidade privada). No entanto, o fator mais presente é o trabalho, já que $77,5 \%$ pretendem trabalhar para se manter na universidade pública e $63,1 \%$ tencionam trabalhar para se manter na universidade privada.

Essa estratégia pode ser confirmada pela alta porcentagem de jovens que pretendem conciliar trabalho e estudo após o ensino médio $(88,3 \%)$. Por outro lado, a porcentagem dos nem-nem é de apenas $0,4 \%{ }^{20}$. 0 foco somente no trabalho corresponde a apenas 5,1\% dos entrevistados, e o foco somente no estudo (trajetória típica da classe média universitária brasileira) corresponde a apenas 6,1\% dos mesmos $^{21}$, conforme tabela 3.

20 - As pesquisas que trabalham com essa noção analisam principalmente o público que já abandonou a escola.

21- Em futuros trabalhos, pretendemos comparar essas expectativas entre estudantes do ensino público e privado. 
Tabela 3: Intenções de trabalhar e seguir estudando (em \%)

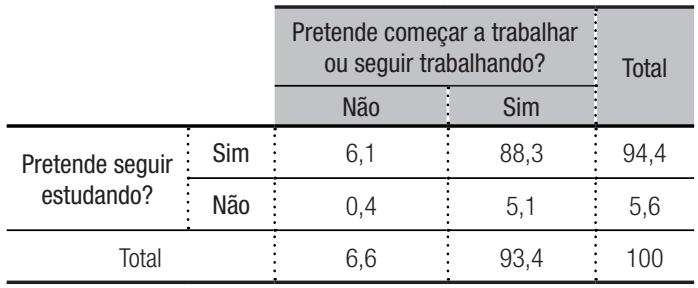

Qui-quad. $=0,255^{\mathrm{a}} \mathrm{df}(1)$ sig. 0,613

Esse dado nos leva a concluir acerca de um dilema dos jovens: embora a necessidade de trabalhar seja a principal dificuldade apontada para a continuidade de seus estudos, por sua vez, o ingresso no mercado de trabalho é visto como o principal fator que lhes possibilitaria o ingresso e a manutenção na universidade. Nesse sentido, se a principal estratégia é, ao mesmo tempo, o principal entrave para a continuidade dos estudos.

Dessa forma, se a principal estratégia é, ao mesmo tempo, o principal entrave para a continuidade dos estudos, há motivos que justifiquem as expectativas otimistas reveladas por esta pesquisa? Para esses jovens, o céu é o limite ou o teto é de vidro? Em outras palavras: a desigualdade de condições e de oportunidades seria um empecilho menor que o esforço individual para superar as dificuldades e atingir os objetivos propostos? $\mathrm{Ou}$, ainda, existe uma dificuldade desses jovens em reconhecer os limites que encontrarão em sua trajetória futura? Seriam as expectativas positivas iguais no conjunto da população estudada?

Para tentar avaliar os percalços implícitos, observamos mais detidamente os seguintes dados: a) a dificuldade imposta pelo trabalho para a continuidade dos estudos; b) a expectativa de seguir estudando; c) a pretensão de fazer faculdade; d) o foco na universidade pública/ privada; e) a avaliação de chances de ingresso na universidade; f) a pretensão de trabalhar ou seguir trabalhando; g) a estratégia de conciliar o trabalho como meio de se manter na universidade. Em seguida, cruzamos esses dados com as seguintes variáveis: 1) experiência atual e/ ou anterior de trabalho; 2) escolaridade e tipo de ocupação dos pais/responsáveis; 3) gênero; 4) autodefinição de raça; 5) autodeclaração de classe. Vejamos a seguir os principais resultados.

0 fato de trabalharem ou já terem trabalhado não tem implicação direta sobre a expectativa de continuidade dos estudos. No entanto, esse fator tem uma influência sobre o ingresso na universidade. Conforme os dados da tabela 4, entre aqueles que não trabalham ou jamais trabalharam, 58,4\% pretendem fazer faculdade; porém, entre aqueles que trabalham ou já trabalharam, esse percentual diminui para 41,6\%.

Tabela 4: Experiência de trabalho $\mathrm{x}$ expectativa de ingresso no ensino superior (em \%)

\begin{tabular}{ccccccc} 
& & & \multicolumn{2}{c}{$\begin{array}{c}\text { Você trabalha ou já } \\
\text { trabalhou? }\end{array}$} & \multirow{2}{*}{ Total } \\
\cline { 2 - 6 } & & & Não & Sim & \\
\hline \multirow{2}{*}{ Pretende fazer faculdade? } & Não & 46,4 & 53,6 & 100 \\
\cline { 2 - 6 } & & Sim & 58,4 & 41,6 & 100 \\
\hline Total & & 5 & 56,5 & 43,5 & 100 \\
\hline
\end{tabular}

Qui-quad. $=10,23^{\mathrm{a}} \mathrm{df}$ (1) sig. 0,001

Entre aqueles que têm foco na pública, $33,8 \%$ trabalham ou já trabalharam, enquanto 66,2\% não possuem experiência atual ou anterior de trabalho. Ademais, entre os que têm foco na universidade pública, $84,8 \%$ pretendem trabalhar, mas, entre aqueles que não têm foco na universidade pública, esse percentual sobe para $94,1 \%{ }^{22}$. Ou seja, a estratégia de conciliar trabalho e estudos torna-se menos forte quando o foco é a universidade pública, seja pelo nível de exigência maior para o ingresso e para a conclusão dos cursos públicos, seja pela dispensa do pagamento de mensalidade.

Ademais, enquanto $10,8 \%$ dos brancos e amarelos consideram que suas chances de ingresso na universidade pública sejam baixas, esse percentual sobe para 17,5\% entre pretos, pardos e indígenas, conforme tabela 5.

22- Qui-quadrado $=15,78$, df (1), sig. 0,000 
Tabela 5: Cor da pele e avaliação de chance de ingresso na universidade pública

\begin{tabular}{ccccccc}
\cline { 2 - 6 } & & $\begin{array}{c}\text { Brancos e } \\
\text { Amarelos }\end{array}$ & $\begin{array}{c}\text { Pretos, Pardos } \\
\text { e Indígenas }\end{array}$ & Total \\
\hline $\begin{array}{c}\text { Chance de ingresso } \\
\text { na universidade } \\
\text { pública }\end{array}$ & Baixa & 10,8 & 17,5 & 14,3 \\
\cline { 2 - 6 } & Alta & 8,4 & 80,8 & 72,8 & 76,5 \\
\hline \multicolumn{2}{c|}{ Total } & & 100 & 100 & 100 \\
\hline
\end{tabular}

Qui-quad. $=13,87^{\mathrm{a}} \mathrm{df}(2)$ sig. 0,0

Da mesma forma, entre os que não se definem como pobres, 11,7\% consideram baixas suas chances de ingresso na universidade pública, mas, entre os que assim se definem, esse percentual sobe para 22,9\%, de acordo com a tabela 6 . A despeito das políticas de cotas nas universidades públicas, as expectativas dos potenciais beneficiários dessa ação afırmativa em relação ao acesso ao ensino superior público são menores.

Tabela 6: Pobreza e avaliação de chance de ingresso na universidade pública

\begin{tabular}{cccccc} 
& & & \multicolumn{2}{c}{ Considera-se pobre } \\
\cline { 2 - 5 } & & & Não & Sim & Total \\
\hline \multirow{2}{*}{$\begin{array}{c}\text { Como você avalia suas } \\
\text { chance de ingresso na }\end{array}$} & Baixa & 11,7 & 22,9 & 14,4 \\
\cline { 2 - 6 } universidade pública? & Média & 79,1 & 68,2 & 76,4 \\
\hline Total & Alta & $9,2 \%$ & 8,9 & 9,1 \\
\hline
\end{tabular}

Qui-quad. $=25,57^{\mathrm{a}} \mathrm{df}(2)$ sig. 0,0

Além da renda, houve diferenças significativas quando observada outra variável socioeconômica importante nas análises educacionais: se $94,8 \%$ do total pretendem seguir estudando, esse percentual cai para 92,3\% entre aqueles cujas mães possuem escolaridade baixa. A pretensão de seguir estudando também é menor entre os jovens cujas mães possuem uma inserção precária no mercado de trabalho ${ }^{23}$ (93,5\% contra 96,1\%).

23- Agregamos os fatores com maior significância estatística: desempregada, assalariada informal e dona-de-casa.
Os dados apresentados permitem concluir que, embora, em um primeiro momento, o céu seja o limite para os jovens quando constroem expectativas, há um teto de vidro que os posiciona desigualmente, impondo limites que reduzem as chances de êxito em sua trajetória. Assim, ainda que conciliar estudo com trabalho seja visto ao mesmo tempo como a maior dificuldade e a principal estratégia, as expectativas e a avaliação de chances se reduzem justamente entre aqueles jovens trabalhadores oriundos de famílias de classe operária com baixa escolaridade, negros e que se autodefinem como pobres. Em outras palavras, suas expectativas com os estudos são mais baixas, a avaliação de chances, mais pessimista, e as dificuldades esperadas, maiores.

\section{Considerações finais}

Contrariando a hipótese inicial, as maiores dificuldades apontadas pela pesquisa não foram o desalento provocado pela avaliação negativa das chances de ingresso pelos jovens (já que a maioria considera que sua chance seja média), o mau desempenho escolar ou a condição financeira (já que pode superar esse fator limitante por meio do trabalho). Vale ressaltar que as expectativas individuais - positivas ou negativas - que os sujeitos constroem de sua trajetória social são devedoras não apenas das condições objetivas de seu estrato social, mas também das representações ideológicas que são feitas sobre essas chances, difundidas principalmente pela mídia e pelas propagandas oficiais.

Nesse sentido, as expectativas dos sujeitos são devedoras do número de vagas na universidade, que teve um significativo crescimento por meio das políticas governamentais recentes, mas também da ideologia meritocrática baseada na noção de igualdade de oportunidades que as acompanha. Em relação ao primeiro aspecto, o crescimento do número de vagas no ensino superior se deve principalmente à expansão do ensino privado durante os governos de Fernando Henrique 
Cardoso (1995-2002). Durante os governos de Lula/Dilma (desde 2003), embora tenha havido expansão do número absoluto de vagas nas universidades federais, houve também forte estímulo ao setor privado por conta do Prouni e do FIES (LIMA, 2012; SOUZA MARTINS, 2012; TRÓPIA, 2009). Quanto ao segundo, as políticas recentes de acesso ao ensino superior vêm acompanhadas de uma intensa campanha publicitária que vem reforçando a ideologia da meritocracia: "a oportunidade é de todos, o mérito é seu", diz um das últimas propagandas sobre a expansão de vagas veiculada pelo Ministério da Educação (MEC) na mídia televisiva. Nesse sentido, é possivel afirmar que esses jovens estejam imersos em um contexto de otimismo: o Brasil estaria se desenvolvendo, parte dos setores populares teria se inserido na chamada nova classe média e camadas historicamente excluídas do ensino superior passaram a entrar na universidade.

Sintetizemos nossas principais análises. Em primeiro lugar, cabe ressaltar a centralidade do trabalho na vida dos jovens pesquisados: a) parte significativa deles trabalha ou já trabalhou; b) a grande maioria pretende começar a trabalhar ou seguir trabalhando; c) o trabalho é visto como principal dificuldade para a continuidade dos estudos; d) o trabalho é a principal estratégia para sua manutenção na universidade.

Em segundo lugar, vale mencionar a existência de um dilema tautológico, pois a estratégia encontrada para romper a barreira do acesso ao ensino superior é, ao mesmo tempo, o principal fator que dificulta a continuidade dos estudos. Se ingressar na universidade não parece difícil, a dificuldade de conciliar estudo e trabalho se revela um teto de vidro.

Apesar do significativo desconhecimento de algumas políticas de acesso ao ensino superior do governo federal, os jovens de modo geral avaliam que o ENEM aumentou suas chances de ingresso na universidade e que as cotas (principalmente entre os negros) também cumpriram esse papel. A ampliação do acesso à universidade pelas classes populares por meio de políticas públicas - Prouni e FIES, nas instituições privadas, e Reuni e cotas, nas públicas - permitiu uma diminuição da distância social do ensino superior e da raridade do título universitário ${ }^{24}$ como mecanismo de distinção social. Apesar dos programas governamentais, a meta do Plano Nacional de Educação (PNE Lei no $10.172 / 2001$ ) de aumentar a proporção de jovens de 18 a 24 anos matriculados em curso superior para 30\% até 2010 esteve longe de ser atingida. Segundo o IBGE, esse percentual era de 13\% em 2009.

Embora os jovens não considerem suas chances de ingresso no ensino superior como altas (principalmente na universidade pública), tampouco as consideram baixas. Essa expectativa convive com uma avaliação de que suas chances são médias, o que atesta o reconhecimento de certas dificuldades que devem ser superadas para atingir esse objetivo. Sendo assim, a resignação à exclusão, ou seja, a autoeliminação ou "eliminação sem exame", a que fazem referência Bourdieu e Passeron (1975), não é predominante nesse grupo. Ao contrário, o resultado indica que os jovens participarão da seleção e tentarão driblar as dificuldades que esperam encontrar.

Retornando à questão posta, se o limite é o céu ou se o teto é de vidro, foi possivel formular algumas hipóteses: a expectativa em relação à continuidade dos estudos é alta, o que faz pensar inicialmente que o desejo desses jovens está acima da avaliação de suas chances concretas, o que reproduz a ideologia do mérito e do dom, mas principalmente do esforço individual que possibilitaria superar as condições do ponto de partida; nesse sentido, o céu seria o limite. Porém, há um reconhecimento dos percalços derivados da posição na estrutura de classes e, além disso, a expectativa e as chances diminuem segundo diversas variáveis; nesse sentido, o teto é de vidro.

Embora a maioria dos jovens pesquisados se considere de classe média, a

24- Pelo menos em algumas carreiras, como as licenciaturas. 
perspectiva de se dedicar somente aos estudos trajetória típica da classe média universitária brasileira - tampouco está no horizonte desses jovens. Ademais, apesar de haver certo clima de otimismo, a avaliação das chances não é baixa nem alta, e o teto de vidro se aproxima desses jovens como indicativo de que a trajetória escolar segue sendo um dos mecanismos mais poderosos de reprodução das desigualdades socioeconômicas e das relações de classe. Uma pesquisa comparativa entre jovens de escolas públicas e privadas avançaria nessa questão.

Em suma, apesar do céu prometido pelo mito do discurso meritocrático, há um teto de vidro imperceptível em um primeiro momento, mas reconhecido pela dificuldade de conciliar estudo e trabalho, bem como pelas expectativas menores em função de fatores socioeconômicos e étnico-raciais.

\section{Referências}

ALTHUSSER, Louis. Ideologia e aparelhos ideológicos do Estado: notas para uma pesquisa. In: ALTHUSSER, Louis. Sobre a reprodução. Petrópolis: Vozes, 1999. p. 253-294.

ANDRADE, Cibelle Yann; DACHS, José Norberto Walter. Acesso à educação por faixas etárias segundo renda e raça/cor. Cadernos de Pesquisa, São Paulo, v. 37, n. 131, p. 399-422, maio/ago. 2007.

BAUDELOT, Christian; ESTABLET, Roger. La escuela capitalista. Madrid: Siglo Veintiuno, 1975.

BOURDIEU, Pierre; PASSERON, Jean-Claude. A reprodução: elementos para uma teoria do sistema de ensino. Rio de Janeiro: Livraria Francisco Alves, 1975.

CARDOSO, Adalberto. Juventude 'nem nem' e a reprodução da desigualdade no Brasil. In: CONGRESSO LATINO-AMERICANO DE ESTUDOS DO TRABALHO, 7., SÃO PAUL0, 02 A 05 JUL. 2013. ANAIS... SÃO PAULO: ALAST, 2013. V.1.

CATANI, Afrânio Mendes; HEY, Ana Paula; GILIOLI, Renato de Sousa Porto. Prouni: Democratização do acesso às instituições de ensino superior. Revista Educar, Curitiba, n. 28, p. 125-140, 2006.

DAYRELL, Juarez. A escola "faz" juventudes? Reflexões em torno da socialização juvenil. Educação e Sociedade, Campinas, v. 28, n. 100, p. 1105-1128, out. 2007.

LIMA, Márcia. Acesso à universidade e mercado de trabalho: o desafio das políticas de inclusão. In: SOUZA MARTINS, Heloisa Helena; COLLADO, Patricia AlejandraT. Trabalho e sindicalismo: no Brasil e na Argentina. São Paulo: Hucitec, 2012. p. 91-110.

LIMONGI, Fernando; SAMPAI0, Helena Maria Sant'Ana; TORRE, Haroldo. Eqüidade e heterogeneidade no ensino superior brasileiro. Documento de trabalho 1/00. São Paulo: NUPES/USP, 2000.

NERI, Marcelo Cortes. A nova classe média: o lado brilhante da pirâmide. Rio de Janeiro: FGV: CPS, 2010.

PIAGET, Jean; INHELDER, Bärbel. Da lógica da criança à lógica do adolescente. São Paulo: Pioneira, 1976.

POCHMANN, Marcio. Educação e trabalho: como desenvolver uma relação virtuosa? Educação e Sociedade, Campinas, v. 25, n. 87, p. 383-399, maio/ago. 2004.

SAES, Décio Azevedo Marques de. Classe média e escola capitalista. Crítica Marxista, São Paulo, v.1, n. 21, p. 97-112, 2005.

SAVIANI, Dermeval. Escola e democracia. Campinas: Autores Associados, 2009. 
SOUZA, Davisson Charles Cangussu de. Considerações sobre o caráter de classe da estrutura universitária brasileira: desigualdade escolar e condições de acesso. Revista Pensata, v. 2, n. 1, p. 55-71, dez. 2012.

TRÓPIA, Patrícia Vieira. 0 ensino superior em disputa: apoio e alianças de classe à política para o ensino superior no governo Lula. Revista Iberoamericana de Educación, v. 9, p. 1-12, abr. 2009.

Recebido em: 15.02.2014

Aprovado em: 02.09.2014

Davisson Charles Cangussu Souza é professor do curso de graduação e do Programa de Pós-Graduação em Ciências Sociais da Universidade Federal de São Paulo (Unifesp - campus Guarulhos) e coordenador do Grupo de Estudos e Pesquisas Educação, Classes e Conflitos Sociais (Gepecso/Unifesp).

Daniel Arias Vazquez é professor do curso de graduação e do Programa de Pós-Graduação em Ciências Sociais da Universidade Federal de São Paulo (Unifesp - campus Guarulhos) e coordenador do Grupo de Estudos Sociais, Urbanos e Ambientais (GESUA/ Unifesp). 